\title{
Cloacoplasty in a 40-Day-Old Monk Parakeet with Cloacal Prolapse
}

\author{
Guilherme Rech Cassanego ${ }^{1}$, Priscila Inês Ferreira ${ }_{(\mathbb{0}}{ }^{2}$, Carolina Cauduro da Rosa ${ }_{(\mathbb{*})}^{3}$, \\ Fabiano da Silva Flores ${ }_{\varpi^{3}}^{3}$ \& Luís Felipe Dutra Corrêa ${ }^{1}{ }^{1}$
}

\begin{abstract}
Background: The monk parakeet (Myiopsitta monachus) is also known as the quaker parrot and belongs to the order Psittaciformes in the family Psittacidae. The cloaca is a posterior orifice common to reproductive, digestive and urinary systems and the cloacal prolapse is the displacement or inversion of its anatomic position. Nowadays, the non-conventional pet market in Brazil is rapidly growing, which demands more skills and competences from an avian veterinarian. This study case has as its main objective to present a 40-day-old monk parakeet (Myiopsitta monachus) with cloacal prolapse, treated using the cloacoplasty technique. It is important to mention that the occurrence of cloacal prolapse in this species and in such an early age is uncommon.

Case: The patient presented 1 day before the physical examination an increased volume in the cloacal region and hematochezia, and diagnosed as cloacal prolapse. For the treatment, wounds were washed using physiological saline solution, ice and sugar were applied in order to reduce the edema, and mineral oil was used for repositioning the cloacal mucosa. Finally, local anesthesia was applied and 2 isolated contralateral sutures were done with the objective of reducing the sphincter's diameter, without compromising the flow of urine and feces. The monk parakeet was treated with antibiotic Avitrin $^{\circledast}$ [oxytetracycline hydrochloride $-8.1 \mathrm{mg} / \mathrm{mL}$ ] and a vermifuge [mebendazole $50 \mathrm{mg} / \mathrm{mL}$ ]. A sample of feces was also obtained and sent to the Laboratory of Avian Pathology Diagnosis. The patient was discharged after 7 days of the treatment, obtaining a favorable result with no further complications.

Discussion: The results of the coproparasitological examination were negative for the samples analyzed; nevertheless, the possibility of a false negative result cannot be totally dismissed. Cloacal prolapse may be related to cases of hypersexual disorder or overexertion to defecate due to intestinal parasites, posture, polyps, enteritis, neoplasm or cloacal hyperplasia. Besides that, endoparasitism is common in captive birds. For the correct treatment, proceed with a cloacoplasty, in which 1 or 2 simple sutures are made separated laterally in both sides, promoting the narrowing of the orifice. The surgeries such as the cloacoplasty are currently being defended, but in most cases as an adjuvant therapy. Cloacal prolapse in birds is a disease considered as an intestinal emergency. The techniques presented in this work demand sedation or anesthesia for the patient, which were not authorized by the tutor due to the high risk involved. However, due to the characteristic of domestication and docile behavior of the bird, it was possible to perform the 2 sutures with a local anesthetic block only. Cloacal prolapse is relatively common in adult psittacine birds, but uncommon in monk parakeets and young birds. The treatment performed was effective for the monk-parakeet presented in this study case. The authors, however, would like to strongly reinforce the need to identify the cause of cloacal prolapse in order to properly treat it. The importance of correctly identifying the anatomy of a psittacine bird as well as applying precisely the suture techniques are the most important conclusions obtained, making both the identification of the problem and its solution through surgical intervention a simpler and successful process.
\end{abstract}

Keywords: birds, endoparasites, suture, wild. 


\section{INTRODUCTION}

Throughout the last decades, the non-conventional pet market is growing rapidly, which contributes for improving the conditions for maintaining and fostering wild exotic birds, with relevant evolution related to nutrition, zootechnics and sanitary conditions. The monk parakeet (Myiopsitta monachus) is also known as the quaker parrot and belongs to the order Psittaciformes in the family Psittacidae [5].

The cloaca is a posterior orifice common to reproductive, digestive and urinary systems [7]. The cloacal prolapse is the displacement or inversion of its anatomic position and must be differentiated from an oviduct or rectal prolapse, or even from the hypertrophy of the cloacal mucosa during the reproductive period, as in the case of the vasa parrot (Coracopsis vasa) [8].

Cloacal prolapse is a condition that commonly occurs in psittacine birds, with a higher frequency in cockatoos (Cacatuidae) and african gray parrots (Psittacus erithacus) [11]. However, rapid treatment is necessary to avoid the necrosis of ectopic tissues [8], since this condition is typically dangerous and potentially fatal if not treated $[1,4]$.

In Brazil, the non-conventional pet market is rapidly growing, which demands more skills and competences from an avian veterinarian [5]. This report describes a case of a 40-day-old monk parakeet (Myiopsitta monachus) with cloacal prolapse, and which was treated with cloacoplasty technique. Cloacal prolapse is relatively common in adult psittacine birds, but uncommon in monk parakeets and young birds

\section{CASE}

A 40-day-old monk parakeet was received at the Veterinary Hospital, with complaints regarding to an increased volume in the cloacal region (Figure 1A) and hematochezia, which started 1 day before. The patient used to feed exclusively with food for parrot chicks. After clinical evaluation, the cloacal prolapse was diagnosed. For starting the treatment, Buscofin Compound $^{1}$ [sodic dipyrone $500 \mathrm{mg}$ and Hyoscine 4 $\mathrm{mg}$ ] was used, mainly because of its antispasmodic and analgesic effect, in a single dose [ volume of 0.0015 $\mathrm{mL}$ (equivalent to $1.5 \mu \mathrm{L}$ ) diluted in $0.1 \mathrm{~mL}$ of distilled water], administered by intramuscular route. Later, sugar was used over the prolapsed region for $5 \mathrm{~min}$, followed by ice cubes for additional $5 \mathrm{~min}$. Then, the region was washed with physiological saline solution, and 2 drops of mineral oil were applied, repositioning the cloacal mucosa with the aid of a thermometer.

After repositioning the structure, lidocaine gel was applied over the cloacal orifice in order to make 2 isolated contralateral sutures using a non-absorbable, synthetic monofilament suture thread 5-0 (Nylon) ${ }^{2}$, with the objective of reducing the sphincter's diameter, without compromising the flow of urine and feces. The treatment consisted of an antibiotic ${ }^{3}$ [oxytetracycline hydrochloride $-8.1 \mathrm{mg} / \mathrm{mL}$, one drop orally, BID for 5 days] and a vermifuge ${ }^{3}$ [mebendazole $-50 \mathrm{mg} / \mathrm{mL}$, administered in the drinking water, diluting 4 drops in $50 \mathrm{~mL}$, changed every $12 \mathrm{~h}$ and offered during 3 days]. A sample of feces was also obtained and sent to the Laboratory of Avian Pathology Diagnosis. The suture was removed in 7 days (Figure 1B).

\section{DISCUSSION}

The patient was discharged from the Veterinary Hospital after 7 days, obtaining excellent results and with no further complications being related. After 15 days, the patient returned for evaluation and adequation of its diet, in which fruits, vegetables and seeds were introduced. The nutrition of psittacine birds is composed by seeds, sprouts, chestnut, jelly palm, fruits, flowers and other vegetables. For chick parrots, it is recommended to offer specific chick parrot food until they are 60-day-old [5].

The results of the coproparasitological examination were negative for the samples analyzed; nevertheless, the possibility of a false negative result cannot be totally dismissed. The reliability of the diagnosis of parasitic diseases depends on several factors, such as the obtaining of samples, conservation, storing and transport to the laboratory, methods used in the laboratory for diagnosing and the time for storing the feces, since eggs from numerous parasites may hatch liberating larvae [10].

Cloacal prolapse may be related to cases of hypersexual disorder or overexertion to defecate due to intestinal parasites, posture, polyps, enteritis, neoplasm or cloacal hyperplasia [5] and is most commonly seen in adult birds. Besides that, endoparasitism is common in captive birds [10].

The zearalenone is a mycotoxin which may cause cloacal prolapse in birds, and the contamination through this toxin generally occurs before the harvest, as the grain grows, phase in which fungi from the 


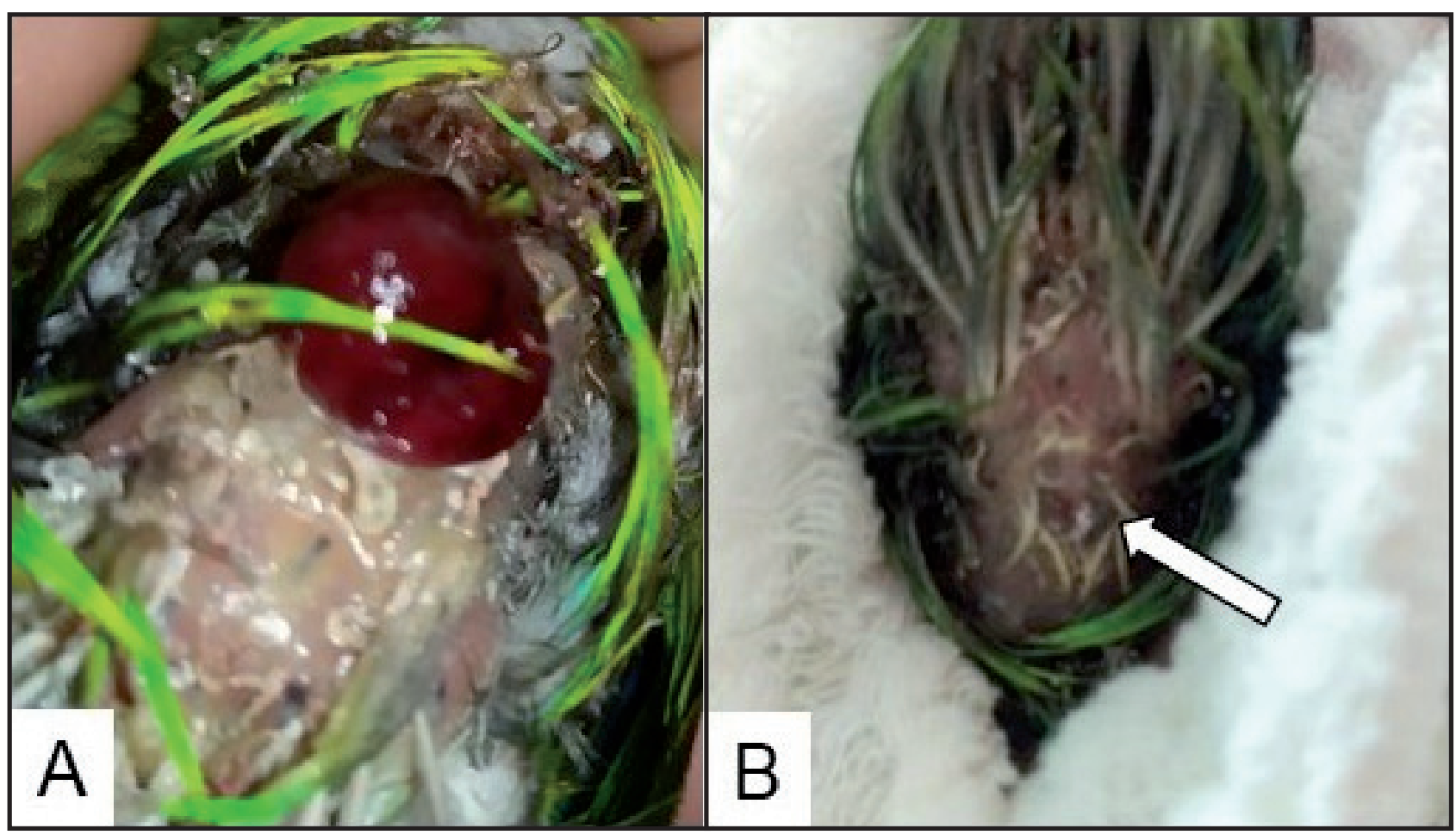

Figure 1. A- Patient in the tutor's hands during its arrival with cloacal prolapse. B- After 7 days of treatment (an arrow points in the direction of the cloaca).

gender Fusarium sp. find a favorable environment for their development [2]. Also, the risk of cloacal prolapse in laying hens rises when there is a deficiency in calcium [9].

In a retrospective study, including 90 birds with diseases and submitted to surgical interference during a period of 8 years, only 2 were treated for cloacal prolapse. In international literature, cockatoos are considered the psittacine birds most affected by cloacal prolapse. However, there is the possibility of this species, considered the most affected, may not be the most predisposed as mentioned, but the ones that are most present in the local where the study occurred [3]. This condition is found frequently in laying hens and may occur before, during or immediately after laying eggs [1].

For the correct treatment, it is firstly indicated cleaning the region with physiological saline solution and lubricate for repositioning the structure. In case where necrotic tissues are found, it is necessary to remove them before continuing the procedure [8]. Then, proceed with a cloacoplasty, in which 1 or 2 simple sutures are made separated laterally in both sides, promoting the narrowing of the orifice; in case where a permanent narrowing is necessary, an incision must be done and the skin in both sides of the cloaca must be removed [5,7]. Surgeries such as the cloacoplasty are currently being employed, but in most cases only as an adjuvant therapy [11].

Another indication, but applied in relapse cases, is the cloacopexy, in which an incision in the abdominal region over the ventral midline is made with a scalpel, separating the skin from the muscles, then a swab is inserted from the cloaca to the local where the incision was made in the abdominal wall and with a non-absorbable, synthetic monofilament suture thread the serous layer of the cloaca is anchored to the abdominal muscles [5]. Besides that, it is not indicated to make neither tobacco-pouch suture nor circular suture in birds, since in most cases their cloacal orifice is flattened horizontally, in a lip format, which differs them from mammals, where the anus is round [7]. Nonetheless, some authors include the tobacco-pouch suture as one of the options for correcting the problem [8]. It is important to mention that, for the successful treatment in cases of cloacal prolapse, other causes may be investigated, identified and treated [4].

Cloacal prolapse in birds is a disease considered as an intestinal emergency, which tends to be more difficult to solve than the cases found in cats and dogs, since birds have higher sensitivity to stressful stimulus and higher metabolism [6]. The techniques 
presented in this work demand sedation or anesthesia for the patient, which were not authorized by the tutor due to the high risk involved. However, due to the characteristic of domestication and docile behavior of the bird, it was possible to perform the 2 sutures with a local anesthetic block only.

Cloacal prolapse is relatively common in adult psittacine birds, but uncommon in monk parakeets and young birds. The treatment used was efficacious for the patient in the present study case. The authors, however, would like to strongly reinforce the need to identify the cause of cloacal prolapse in order to properly treat it.
The importance of correctly identifying the anatomy of a psittacine bird as well as applying precisely the suture techniques are the most important conclusions obtained, making both the identification of the problem and its solution through surgical intervention a simpler and successful procedure.

\section{MANUFACTURERS}

${ }^{1}$ União Química Farmacêutica Nacional S.A. Embu-Guaçu, SP, Brazil. ${ }^{2}$ Shalon Fios Cirúrgicos Ltda. Goiânia, GO, Brazil.

${ }^{3}$ Coveli Indústria e Comércio Ltda. Duque de Caxias, RJ, Brazil.

Declaration of interest. The authors report no conflicts of interest. The authors alone are responsible for the content and writing of paper.

\section{REFERENCES}

1 Biswas D. \& Seifuddin A.K.M. 2014. Cloaca-vent Prolapsed in a Lutino Fischer's Love Bird (Agapornis Fischeri). Veterinary Science Development. 4(1): 13-14. doi: 10.4081/vsd.2014.5141

2 Bünzen S. \& Haese D. 2006. Controle de Micotoxinas na alimentação de aves e suínos. Revista Eletrônica Nutritime. 3(1): 304-309.

3 Castro P.F., Fantoni D.T. \& Matera J.M. 2013. Estudo retrospectivo de afecções cirúrgicas em aves. Pesquisa Veterinária Brasileira. 33(5): 662-668. doi:10.1590/\$0100736X2013000500018

4 Dutton T.A.G., Forbes N.A. \& Carrasco D.C. 2016. Cloacal Prolapse in Raptors: Review of 16 Cases. Journal of Avian Medicine and Surgery. 30(2): 133-140. doi: 10.1647 / 2015-091

5 Grespan A. \& Raso T.F. 2014. Psittaciformes (Araras, Papagaios, Periquitos, Calopsitas e Cacatuas). In: Cubas Z.S., Silva J.C.R. \& Catão-Dias J.L. (Eds). Tratado de Animais Selvagens: Medicina Veterinária. 2.ed. São Paulo: Roca, pp.614-654.

6 Harrison G.J., Lightfoot T. \& Flinchum G. 2006. Emergency and Critical Care. In: Harrison G.J. \& Lightfoot T.L. (Eds). Clinical Avian Medicine. v.1. Palm Beach: Spix Publishing, pp.213-231.

7 Macwhirter P. 2010. Anatomia, Fisiologia e Nutrição básica. In: Tully Jr. T.N., Dorrestein G.M. \& Jones A.K. (Eds). Clínica de Aves. 2.ed. Rio de Janeiro: Elsevier, pp.78-82.

8 Moraillon R., Legeay Y., Boussarie D. \& Sénécat O. 2013. Manual Elsevier de Veterinária: Diagnóstico e Tratamento de Cães, Gatos e Animais Exóticos. 7.ed. Rio de Janeiro: Elsevier, pp.1801-1802.

9 Silva D.C., Castro I.D.K., Sprenger L.K. \& Slomp M.N. 2019. Influência da Deficiência de Cálcio no Desempenho e Qualidade de Ovos de Galinhas Poedeiras em Sistema Semi-Intensivo na Região Sudeste do Paraná. Revista de Estudos Vale do Iguaçu. 1(33): 57-68.

10 Snak A., Lenzi P.F., Agostini K.M., Delgado L.E., Montanucci C.R. \& Zabott M. V. 2014. Análises Coproparasitológicas de Aves Silvestres Cativas. Ciência Animais Brasileira. 15(4): 502-507. doi: 10.1590/1809-6891v15i425797

11 Zaheer O., Beaufrère H., Jajou S. \& Gardhouse S. 2020. Asymmetrical Cloacoplasty for the Chronic Cloacal Prolapse in Psittaciformes: A Case Series. Journal of Avian Medicine and Surgery. 34(2): 172-180. doi: 10.1647/10826742-34.2.172 